\title{
PREPARATION OF MESOPOROUS ACTIVATED CARBON FROM JACKFRUIT PPI-1 WASTE AND DEVELOPMENT OF DIFFERENT SURFACE FUNCTIONAL GROUPS
}

\author{
T. V. Nagalakshmi ${ }^{1,}{ }^{*}$, K. A. Emmanuel ${ }^{2}$, Ch. Suresh Babu ${ }^{3}$, Ch. Chakrapani ${ }^{4}$, \\ P. Paul Divakar ${ }^{5}$
}

${ }^{1}$ Department of chemistry, Acharya Nagarjuna University, Nagarjuna nagar, Guntur-522510, A.P., India.

${ }^{2}$ Department of Chemistry, Sir C R Reddy Autonomous College, Eluru-534 007, A.P., India.

${ }^{3}$ Department of Science \& Humanities, Eluru College of Engineering \& Technology, Eluru-534004, A.P., India.

${ }^{4}$ Department of Basic science \& Humanities, Gudlavalleru Engineering College, Gudlavalleru521356, A.P., India

${ }^{5}$ Department of Physics, Sir C. R. Reddy Autonomous College, Eluru 534007, India

*E-mail address: mannava_laxmi@yahoo.co.in

Keywords: Jackfruit PPI-1, SEM, TPD, activated carbon

ABSTRACT. Jackfruit PPI-1 variety was selected as source of lignocellulose material. Its rind and pulp waste was used as precursor for preparation of activated carbon. $\mathrm{K}_{2} \mathrm{CO}_{3}$ was selected as activating agent to prepare activated carbon. Various carbons were prepared by changing the impregnation ratio (IR) at different temperatures. Activated carbon prepared at $600^{\circ} \mathrm{C}$ and at IR1 had good BET surface area $\left(987 \mathrm{~m}^{2} \mathrm{~g}^{-1}\right)$ and yield $(61.97 \%)$. In order to introduce different functional groups, this carbon was divided into two parts. One part was subjected to liquid phase

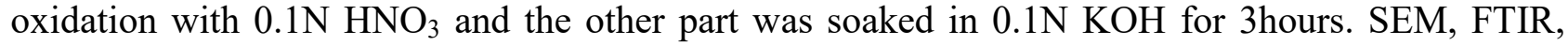
TPD, XRD and TGA analyses were done to identify surface morphological changes, nature of functional groups and thermal stability of activated carbons.

\section{INTRODUCTION}

Agricultural waste materials can be converted into useful activated carbon adsorbents. If not managed properly, agricultural wastes become an environmental problem and a hazard for human and animal health. Many researchers used different chemical activating agents like $\mathrm{H}_{3} \mathrm{PO}_{4}, \mathrm{H}_{2} \mathrm{SO}_{4}$, $\mathrm{ZnCl}_{2}$ etc., to prepare activated carbon from lignocellulosic materials and applied them in removal of toxic substances from aqueous solution. But all these activating agents are toxic and cause secondary pollution. In the present study, the selected lignocellulosic agricultural waste was activated by $\mathrm{K}_{2} \mathrm{CO}_{3}$ which is not a hazardous chemical and not deleterious as it is frequently used for food additives. The aim of this study is to prepare activated carbon and to introduce different surface functional groups onto the prepared carbon. As surface functional groups play a vital role in attracting different types of toxic substances and give feasibility for their adsorptive removal [1].

\section{MATERIALS AND METHODS}

\subsection{Material}

Jackfruit PPI-1 variety was collected from state horticulture mission, Paderu, Visakhapatnam, A.P., India. The rind and pulp waste of fruit was used as precursor for preparation of activated carbon. The waste was washed with hot distilled water to remove dirt and dehydrated at $105^{\circ} \mathrm{C}$ until constant weight was obtained. This dried waste was then cut into small pieces and named as 'JWM'. 


\subsection{Preparation of activated carbon}

JWM was mixed with $\mathrm{K}_{2} \mathrm{CO}_{3}$ solution in different impregnation ratios, 0.5, 1 and 1.5. Impregnation ratio (IR) was given by weight of $\mathrm{K}_{2} \mathrm{CO}_{3}(\mathrm{~g})$ in solution/weight of JWM in $\mathrm{g}$. These mixtures were dehydrated in an oven overnight at $105^{\circ} \mathrm{C}$. The impregnated JWMs were carbonized in uniform nitrogen flow to different final temperatures, 500, 600 and $700^{\circ} \mathrm{C}$. The heating was provided at rate of $10^{\circ} \mathrm{C} \mathrm{min}^{-1}$. The prepared activated carbons were cooled to room temperature and washed with hot distilled water to remove remaining chemical and filtered. The washing and filtration steps were repeated until the filtrate showed neutral $\mathrm{pH}$. All activated carbons were sieved to $45 \mathrm{mesh}$ and were named in accordance with their activation temperatures $\mathrm{JC}_{500}, \mathrm{JC}_{600}$ and $\mathrm{JC}_{700}$. For comparative study of effect of activating agent on surface morphology, another sample of JWM is heated to $600^{\circ} \mathrm{C}$ under similar conditions without impregnation and it was named as $\mathrm{JC}_{\text {Non-activated. }}$.

In order to introduce different functional groups, $\mathrm{JC}_{600}$ (at $\mathrm{IR} 1$ ) was divided into two parts. One part was subjected to liquid phase oxidation with $0.1 \mathrm{~N} \mathrm{HNO}_{3}$ and the other part was soaked in $0.1 \mathrm{~N} \mathrm{KOH}$ for 3 hours. Both carbons were filtered and washed with distilled water until filtrate showed neutral $\mathrm{pH}$. These carbons were dehydrated in an oven overnight at $105^{\circ} \mathrm{C}$ and named as ' $\mathrm{JC}_{\mathrm{HNO}_{3}}$ ' and ' $\mathrm{J} \mathrm{KOH}_{\mathrm{KOH}}$ ', indicating the chemical activating agent.

\subsection{Characterization of prepared activated carbons}

The pore structures of the resulting carbons were analyzed using $\mathrm{N}_{2}$ adsorption, $\mathrm{X}$-ray diffraction (XRD), scanning electron microscope (SEM). Surface area was calculated by BrunauerEmmett-Teller (BET) equation. Thermal stability of carbons was analyzed by thermogravimetric analysis (TGA) and temperature programmed desorption (TPD) studies. Point of zero charge was determined for $\mathrm{JC}_{600}$ (at IR1), $\mathrm{JC}_{\mathrm{HNO}_{3}}$ and $\mathrm{JC}_{\mathrm{KOH}}$.

\subsection{Determination of point of zero charge (PZC)}

Point of zero charge is the $\mathrm{pH}$ at which the external surface charge is zero [2]. $50 \mathrm{ml}$ of $0.01 \mathrm{~N} \mathrm{NaCl}$ solution was placed in a closed Erlenmeyer flask. The $\mathrm{pH}$ was adjusted to a value between 2 and 12 by adding $0.1 \mathrm{~N} \mathrm{HCl}$ or $0.1 \mathrm{~N} \mathrm{NaOH}$ solutions. Then $0.15 \mathrm{~g}$ of carbon sample was added and the final $\mathrm{pH}$ measured after $48 \mathrm{~h}$ under agitation at room temperature. The $\mathrm{PZC}$ is the point where the curve $\mathrm{pH}$ (final) $\mathrm{vs}$. $\mathrm{pH}_{\text {(initial) }}$ crosses the line $\mathrm{pH}_{\text {(final) }}=\mathrm{pH}_{\text {(initial) }}$ taken as the $\mathrm{PZC}$ of the given carbon [3].

\section{$2.5 \mathrm{~N}_{2}$ adsorption}

The pore structure characteristics of prepared carbons were determined by nitrogen adsorption at $-196^{\circ} \mathrm{C}$ by a Quanta chrome instrument (Nova 2200). Prior to gas adsorption measurements, the carbon was degassed at $150^{\circ} \mathrm{C}$ in a vacuum condition for $24 \mathrm{~h}$. Nitrogen adsorption isotherms were measured over a relative pressure $\left(P / P_{\mathrm{o}}\right)$ range from approximately 0.03 to 0.995 . The BET surface area was determined by means of the standard BET equation applied in the relative pressure range from 0.06 to 0.3 . The total pore volume was calculated at a relative pressure of approximately 0.995 and at this relative pressure all pores were completely filled with nitrogen gas. The density functional theory (DFT) pore size distribution of all carbon samples were obtained based on nitrogen adsorption isotherms with medium regularization.

\subsection{SEM analysis}

A scanning electron microscope SEM Hitachi- S520 (OXFORD LINK-ISIS) was used to study the texture of the surface of activated carbons.

\subsection{FTIR analysis}

The surface chemistry characterization of each activated carbon was performed Fourier Transform Infrared Spectroscopy (FTIR) to identify its surface functional groups. FTIR spectra were recorded on Thermo Nicolet Nexus 670 spectrometer in the wavenumber range $400-4000 \mathrm{~cm}^{-1}$. To prepare pellets, samples were first ground to powder in an agate mortar and then 
mixed with $\mathrm{KBr}$ at a mass ratio of 1:500. A hydraulic press was used to press the resulting mixtures to discs of $10 \mathrm{~mm}$ in diameter at $10 \mathrm{MPa}$ for $5 \mathrm{~min}$.

\subsection{TPD analysis}

TPD analysis was performed on MICROMERITICS CHEMISORB 2750 instrument. Activated carbon samples were kept in high pure Helium flow for 10 minutes. Gas changed to $10 \% \mathrm{NH}_{3}$ in Helium at a rate of $30 \mathrm{ml} \mathrm{min}^{-1}$ flow. $\mathrm{NH}_{3}$ adsorbed for 30 minutes . Gas changed to pure Helium $\left(30 \mathrm{ml} \mathrm{min}^{-1}\right)$ and physisorbed ammonia was removed for stable baseline status.

\subsection{TGA analysis}

The thermogravimetric analysis (TGA) experiments were performed on a SDT Q 600 TGA analyzer (TA instrument). Each time, activated carbon sample was heated from room temperature to $900^{\circ} \mathrm{C}$ under nitrogen atmosphere at a heating rate of $10^{\circ} \mathrm{C} \mathrm{min}^{-1}$.

\subsection{XRD analysis}

Powder X-ray diffraction patterns were recorded on a Philips: PW1830 at $30 \mathrm{kV}$ and $15 \mathrm{~mA}$ ( $\mathrm{Cu} \mathrm{K \alpha}$ radiation) at a step size of $0.01^{\circ}$ and at a wavelength $0.154 \mathrm{~nm}$.

\section{RESULTS AND DISCUSSION}

Proximate analysis JWM was given in Table 1. This analysis indicated that the precursor used in this study has high carbon content; approximately $39 \%$ and low ash content about $2 \%$. Hence JWM was used as activated carbon precursor.

Table1. Proximate analysis of JWM.

\begin{tabular}{|l|l|}
\hline Material & Weight (\%) \\
\hline Moisture & 6.82 \\
\hline Volatile & 51.37 \\
\hline Ash & 2.14 \\
\hline Fixed carbon & 39.67 \\
\hline
\end{tabular}

\subsection{Yield of activated carbon}

The yield of activated carbon is defined as the ratio of the weight of the resultant activated carbon to that of original precursor with both weights on a dry basis [4]. In every case, the yield of activated carbons obtained by $\mathrm{K}_{2} \mathrm{CO}_{3}$ activation was higher than fixed carbon content of proximate analysis. Jackfruit waste contains natural polymers like cellulose, lignin and hemicellulose [5]. During carbonization process these polymeric structures decompose and liberate hydrogen, oxygen, nitrogen and other elements in the form of tar and gases. The presence of $\mathrm{K}_{2} \mathrm{CO}_{3}$ in the interior of JWM might have restricted the formation of tar by forming cross-links and inhibited the shrinkage of precursor material by occupying certain substantial volumes [6]. $\mathrm{K}_{2} \mathrm{CO}_{3}$ will be reduced in inert atmosphere by carbon to give elemental potassium and carbon monoxide $[7,8,9]$.

$$
\mathrm{K}_{2} \mathrm{CO}_{3}+2 \mathrm{C} \rightarrow 2 \mathrm{~K}+3 \mathrm{CO}
$$

Hence potassium will be intercalated between the graphite layers or form graphitepotassium intercalation compounds [10]. The presence of intercalated potassium inhibited the shrinkage of carbon during activation process at elevated temperatures. In hot distilled water washing process of prepared activated carbon, potassium was removed and left micropores. As a result the surface area of impregnated activated carbons was also increased when compared with $\mathrm{JC}_{\text {Non-activated }}$. 


\subsection{Nitrogen adsorption}

The effect of activation temperature and impregnation ratio on the BET surface area, micropore volume, and total pore volume were given in Table 2 . The total pore volume, $V_{\text {total, }}$, was calculated from nitrogen adsorption data as volume of liquid nitrogen at a relative pressure of 0.995. The micropore volume, $V_{\text {micro }}$, was determined by DFT method and the mesopore volume, $V_{\text {meso }}$, was obtained by substraction of micropore volume from total pore volume.

Table2. Characteristics and yield of activated carbons prepared from JWM.

\begin{tabular}{|l|c|c|c|c|c|c|}
\hline Sample & $\begin{array}{l}\text { Impregnation } \\
\text { ratio (IR) }\end{array}$ & $\begin{array}{l}\mathrm{S}_{\mathrm{BET}} \\
\left(\mathrm{m}^{2} \mathrm{~g}^{-1}\right)\end{array}$ & $\begin{array}{l}\mathrm{V}_{\text {micro }} \\
\left(\mathrm{cm}^{3} \mathrm{~g}^{-1}\right)\end{array}$ & $\begin{array}{l}\mathrm{V}_{\text {meso }} \\
\left(\mathrm{cm}^{3} \mathrm{~g}^{-1}\right)\end{array}$ & $\begin{array}{l}\mathrm{V}_{\text {total }} \\
\left(\mathrm{cm}^{3} \mathrm{~g}^{-1}\right)\end{array}$ & $\begin{array}{l}\text { Yield } \\
(\%)\end{array}$ \\
\hline $\mathrm{JC}_{500}$ & 0.5 & 198 & 0.101 & 0.096 & 0.197 & 48.12 \\
\hline $\mathrm{JC}_{600}$ & 0.5 & 213 & 0.156 & 0.113 & 0.269 & 45.46 \\
\hline $\mathrm{JC}_{700}$ & 0.5 & 229 & 0.162 & 0.125 & 0.287 & 44.02 \\
\hline $\mathrm{JC}_{500}$ & 1.0 & 765 & 0.408 & 0.142 & 0.55 & 4813 \\
\hline $\mathrm{JC}_{600}$ & 1.0 & 987 & 0.471 & 0.168 & 0.639 & 61.97 \\
\hline $\mathrm{JC}_{700}$ & 1.0 & 602 & 0.412 & 0.132 & 0.544 & 57.61 \\
\hline $\mathrm{JC}_{500}$ & 1.5 & 318 & 0.286 & 0.269 & 0.555 & 52.05 \\
\hline $\mathrm{JC}_{600}$ & 1.5 & 410 & 0.364 & 0.172 & 0.536 & 51.84 \\
\hline $\mathrm{JC}_{700}$ & 1.5 & 312 & 0.282 & 0.167 & 0.449 & 45.36 \\
\hline $\mathrm{JC}_{\text {Non- }}$ & & & & & & \\
activated & - & 114 & - & 0.106 & 0.106 & 43.07 \\
\hline
\end{tabular}

Figure.1 (a) and $1(\mathrm{~b})$ shows isotherms of $\mathrm{JC}_{\text {Non-activated }}$ and $\mathrm{JC}_{500}$ at all impregnation ratios respectively. These fall under type III isotherms based on IUPAC classification. It indicates that these activated carbons had non-porous or macro porous surface. The corresponding DFT plots (shown in Figure. 2) also represented that these carbons do not contain micropores. Figure.1(c) depicts the isotherms of $\mathrm{JC}_{600}$ at all impregnation ratios. These plots resembled type1 isotherms. So these were microporous materials. However the plateau was not reached sharply. This indicates widening of pores. All these isotherms exhibit $\mathrm{H} 4$ hysteresis loop which is characteristic of slit shaped pores. As IR increases, these show combination of type 1 and type 2 isotherms. This indicates simultaneous presence of micro and mesopores. The DFT plot of $\mathrm{JC}_{600}$ (shown in Figure 2(c)) specifies the presence of both micro and mesopores. The isotherm of $\mathrm{JC}_{700}$ (shown in Figure.1 (d )) shows similar trend. However, DFT plot of $\mathrm{JC}_{700}$ (shown in Figure.2 (d)) recorded the presence of macropores also. The reason for structural changes (with respected to pore development) could be explained as follows. 

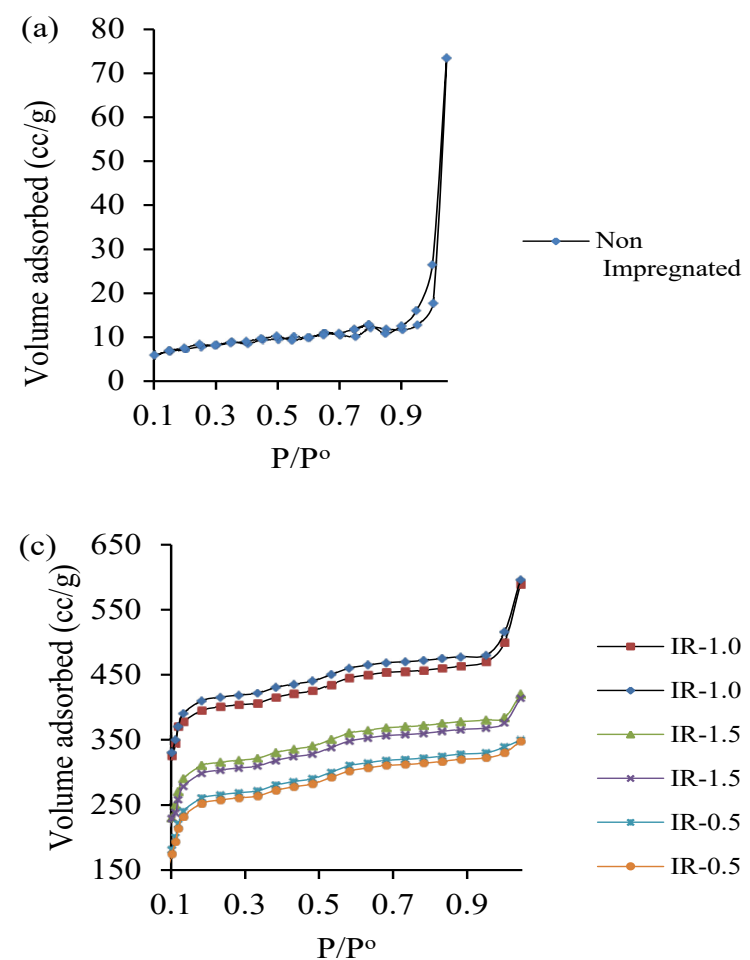
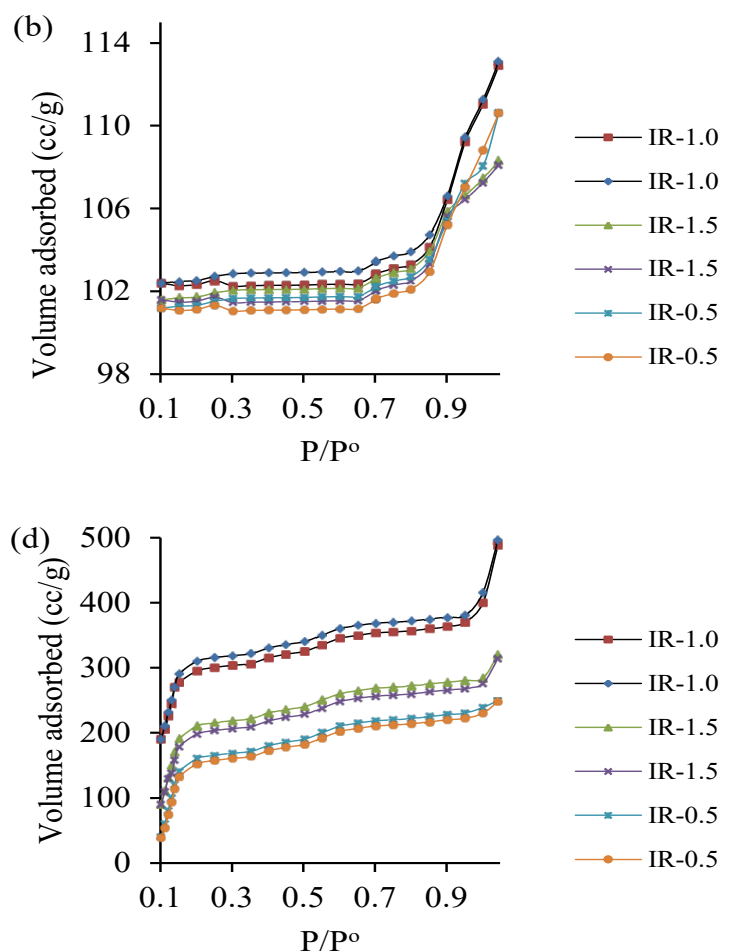

Figure 1. $\mathrm{N}_{2}$ adsorption and desorption isotherms at $77 \mathrm{~K}$ of $\mathrm{JC}_{\text {Non-activated }}$ and $\mathrm{K}_{2} \mathrm{CO}_{3}$ impregnated JWM.

When the ratio of impregnation of $\mathrm{K}_{2} \mathrm{CO}_{3}$ is 0.5 , the activating agent is not sufficient to create required microporous structure in activated carbon to form graphite-potassium intercalation compounds. Hence for all activated carbons $\left(\mathrm{JC}_{500}\right.$ to $\mathrm{JC}_{700}$ at $\left.\mathrm{IR} 0.5\right)$, the surface area was lower than other impregnated carbons. However, for these carbons the $\mathrm{S}_{\mathrm{BET}}$ surface area is greater than $\mathrm{JC}_{\text {Non-activated. }}$ In all activated carbons $\left(\mathrm{JC}_{500}\right.$ to $\mathrm{JC}_{700}$ at $\left.\mathrm{IR} 1\right)$, both micropores and mesopores were developed. Among all activated carbons $\mathrm{JC}_{600}$ at IR1 showed larger surface area, $987 \mathrm{~m}^{2} \mathrm{~g}^{-1}$. At high temperature $700^{\circ} \mathrm{C}$, some micropores might have combined to give large number of mesopores and macropores. As a result the surface area of prepared activated carbons decreased at this temperature. When the IR is 1.5 , the surface area of all activated carbons was greatly decreased. It may be due to the excess activation made by substantial amount of impregnated $\mathrm{K}_{2} \mathrm{CO}_{3}$. In such a case, large number of micropores were combined to give pores with large diameter. The increased mesopores volume for IR 1.5 carbons and development of macropores (shown in Figure.2 (d)) supports conversion of micropores to large sized pores. Similar trend was observed in literature during preparation of activated carbon from $\mathrm{K}_{2} \mathrm{CO}_{3}$ impregnated straw pulp [11]. Hence $\mathrm{JC}_{600}$ (at IR1) with higher surface area was selected for liquid phase activation in further studies. 

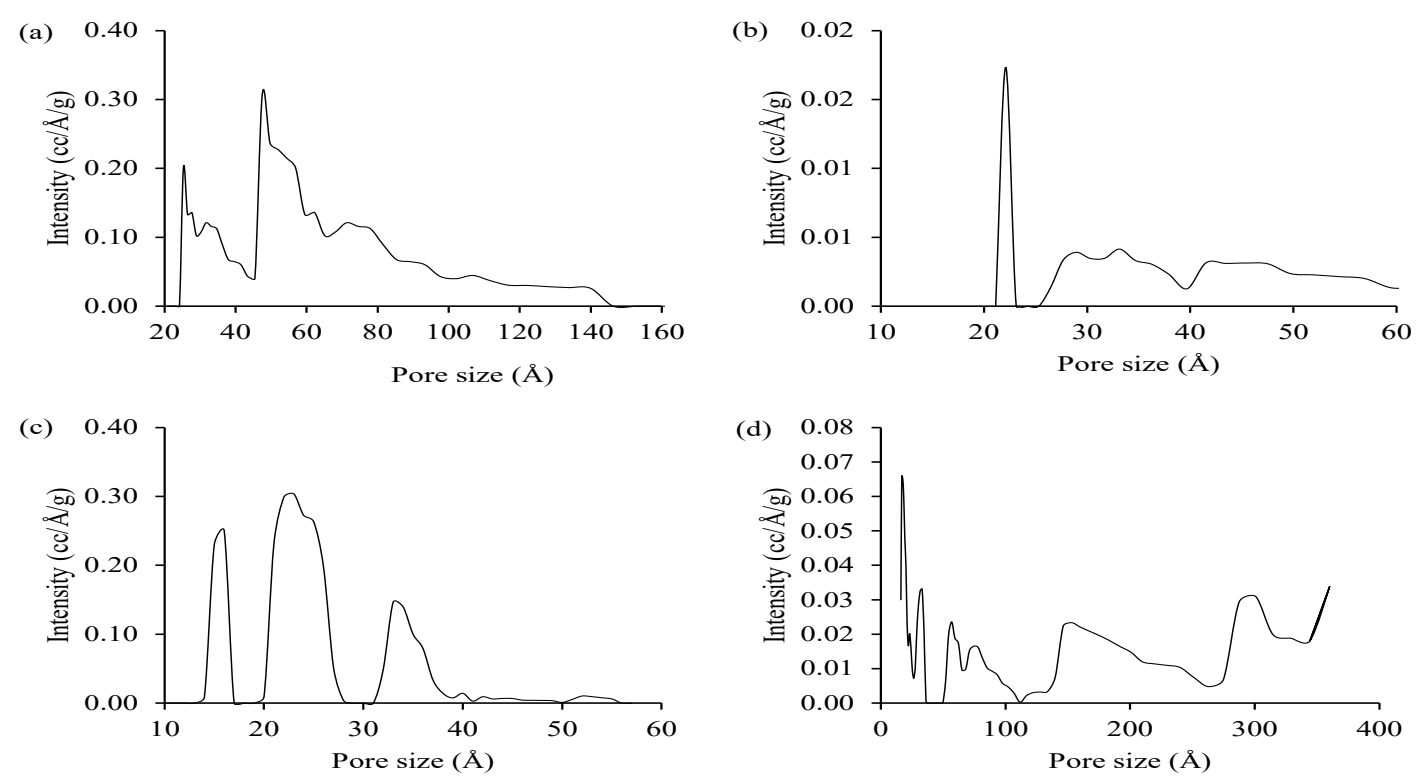

Figure 2. DFT based pore size distribution of activated carbons produced at activation temperatures (a) $500^{\circ} \mathrm{C}$, (b) $600^{\circ} \mathrm{C}$, and (c) $700^{\circ} \mathrm{C}$.

\subsection{TPD analysis}

Figure. 3(a) and 3(b) shows TPD analysis profile for $\mathrm{CO}_{2} \& \mathrm{CO}$ desorption from $\mathrm{JC}_{600}$ (at IR1), $\mathrm{JC}_{\mathrm{HNO} 3}$ and $\mathrm{JC}_{\mathrm{KOH}}$. Surface oxygen groups present on these activated carbons decompose upon heating. They release $\mathrm{CO}_{2}$ and $\mathrm{CO}$ at different temperatures. $\mathrm{CO}_{2}$ peaks result from the decomposition of carboxylic acids [12] at low temperature or lactones at high temperature and anhydrides give both $\mathrm{CO}$ and $\mathrm{CO}_{2}$. Groups like phenols, carbonyls, ethers and quinones originate $\mathrm{CO}$ peaks. Figure. 3(a) clearly shows nitric acid activation introduced sufficient number of oxygen functional groups on carbon surface. When compared with $\mathrm{JC}_{\mathrm{HNO} 3}$ (shown in Figure. 3(a)), $\mathrm{JC}_{\mathrm{KOH}}$ had less number of oxygen functional groups, but much higher than $\mathrm{JC}_{600}$. In both $\mathrm{CO}_{2} \& \mathrm{CO}$ desorption profiles, $\mathrm{JC}_{600}$ showed less oxygen content. However, comparatively, $\mathrm{JC}_{600}$ showed more oxygen content in $\mathrm{CO}$ profile than that of $\mathrm{CO}_{2}$ desorption studies. It may be assumed that during preparation of activated carbon, heat treatments under inert atmosphere at high temperature effectively remove oxygen. But resulted activated carbon has active surface sites which are capable of re-adsorbing oxygen to form previously removed groups [13]. As a whole, $\mathrm{JC}_{600}$ has very less oxygen content which in other words provide more hydrophobic surface. Activated carbons with more hydrophobic surface is one of the required properties for adsorption of disperse dyes from aqueous solution. As disperse dyes have low solubility, they have a tendency to occupy on hydrophobic solid surfaces [14]. In desorption studies of $\mathrm{CO}$ profile, $\mathrm{JC}_{\mathrm{KOH}}$ showed release of $\mathrm{CO}$ at around $750^{\circ} \mathrm{C}$. It evidenced that soaking the activated carbon in potassium hydroxide solution changed the surface chemistry of carbon by introducing different oxygen functional groups. 

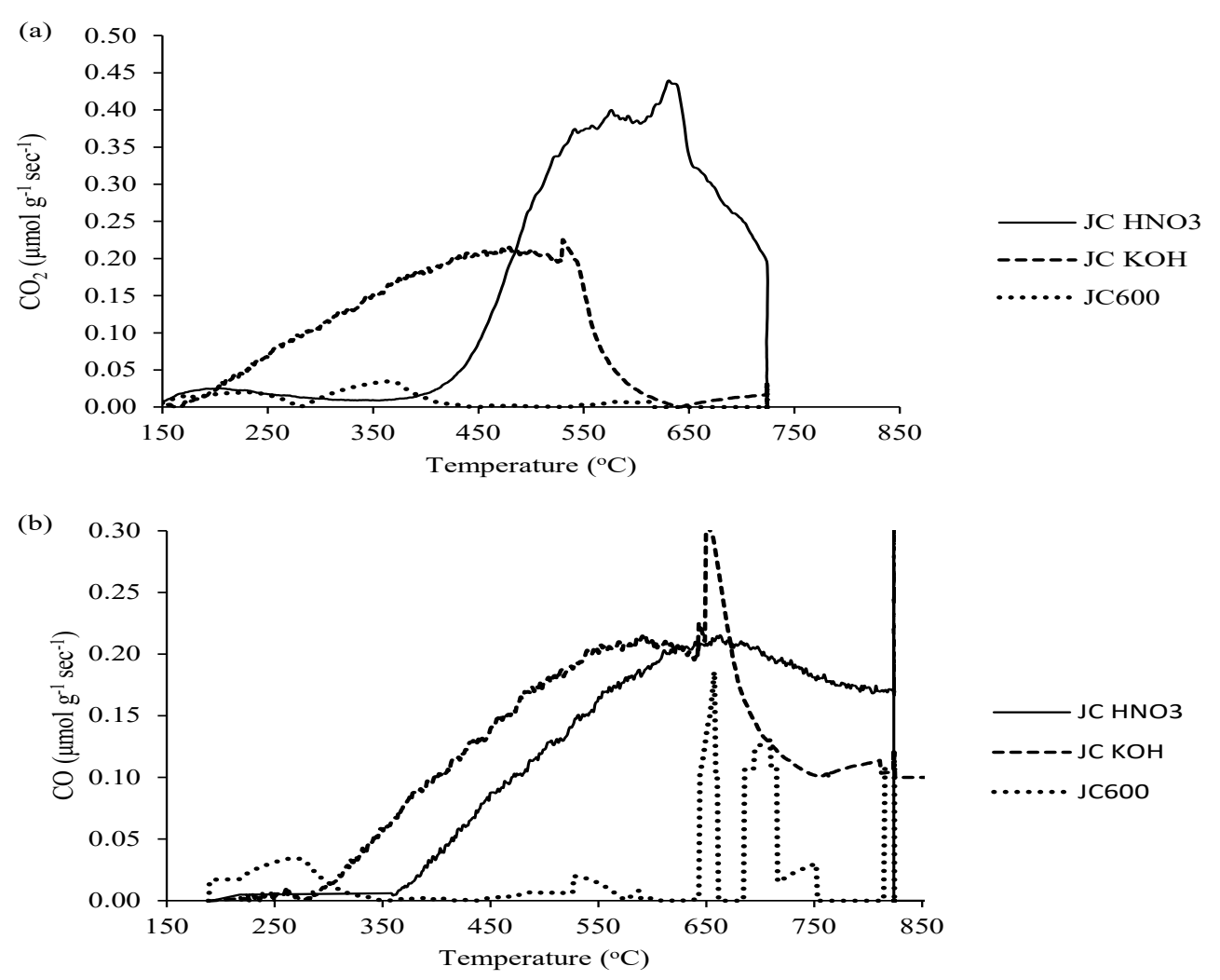

Figure 3. TPD analysis of $\mathrm{JC}_{600}$ (at IR1), $\mathrm{JC}_{\mathrm{HNO}_{3}}$ and $\mathrm{JC}_{\mathrm{KOH}}$; (a) Evolution profiles of $\mathrm{CO}_{2}$ and (b) Evolution profiles of CO.

The PZC values of $\mathrm{JC}_{600}$ (at IR1), $\mathrm{JC}_{\mathrm{HNO}}$ and $\mathrm{JC}_{\mathrm{KOH}}$ were tabulated in Table3. The PZC values of $\mathrm{JC}_{\mathrm{HNO} 3}$ and $\mathrm{JC}_{\mathrm{KOH}}$ were changed from 6.7 to 4 and 10 respectively. It may be due to the change in their surface functional groups generated by liquid phase activation.

Table 3.Point of zero charge values of selected activated carbons.

\begin{tabular}{|l|l|}
\hline Activated carbon & PZC Value \\
\hline $\mathrm{JC}_{600}$ (at IR1) & 6.7 \\
\hline $\mathrm{JC}_{\mathrm{HNO}}$ & 4 \\
\hline $\mathrm{JC}_{\mathrm{KOH}}$ & 10 \\
\hline
\end{tabular}

\subsection{FTIR analysis}

The FTIR spectra of $\mathrm{JC}_{600}$ (at IR 1), $\mathrm{JC}_{\mathrm{HNO}_{3}}$ and $\mathrm{JC}_{\mathrm{KOH}}$ were shown in Figure.4. Bands observed in the range $1100-1450 \mathrm{~cm}^{-1}$ are shown in Figure.4. due to $\mathrm{C}-\mathrm{O}$ stretches in carboxylic acids, anhydrides, lactones, esters, ethers, phenols and epoxides [15,16]. Bands in this region are higher for $\mathrm{JC}_{\mathrm{HNO}}$ and $\mathrm{JC}_{\mathrm{KOH}}$ when compared with $\mathrm{JC}_{600}$. This is in good agreement with $\mathrm{TPD}$ analysis results (shown in Figure.3). A distinct peak was observed at $1580 \mathrm{~cm}^{-1}$ for $\mathrm{JC}_{600}$ only. This is due to polyaromatic $\mathrm{C}=\mathrm{C}$ stretching vibrations in $\mathrm{sp}^{2}$-hybridized carbons $[17,18]$. This indicates the non-polar (hydrophobic) nature of $\mathrm{JC}_{600}$. Bands in the range $1350-1380 \mathrm{~cm}^{-1}$ are due to C-N bond stretching vibrations of aryl amines. As the jackfruit is complex composite material formed of natural polymers, it may contain nitrogenous compounds like amino acids. Bands in the range 2364$2372 \mathrm{~cm}^{-1}$ are attributed to $\mathrm{C}-\mathrm{H}$ stretching due to presence of $\mathrm{CH}_{2}-\mathrm{CO}$-group. Bands around 2800$3000 \mathrm{~cm}^{-1}$ are due to various C-H stretching modes [19]. Bands around $3400-3500 \mathrm{~cm}^{-1}$ are due to $\mathrm{OH}$ stretches in hydroxyl, carboxylic and phenolic groups. 


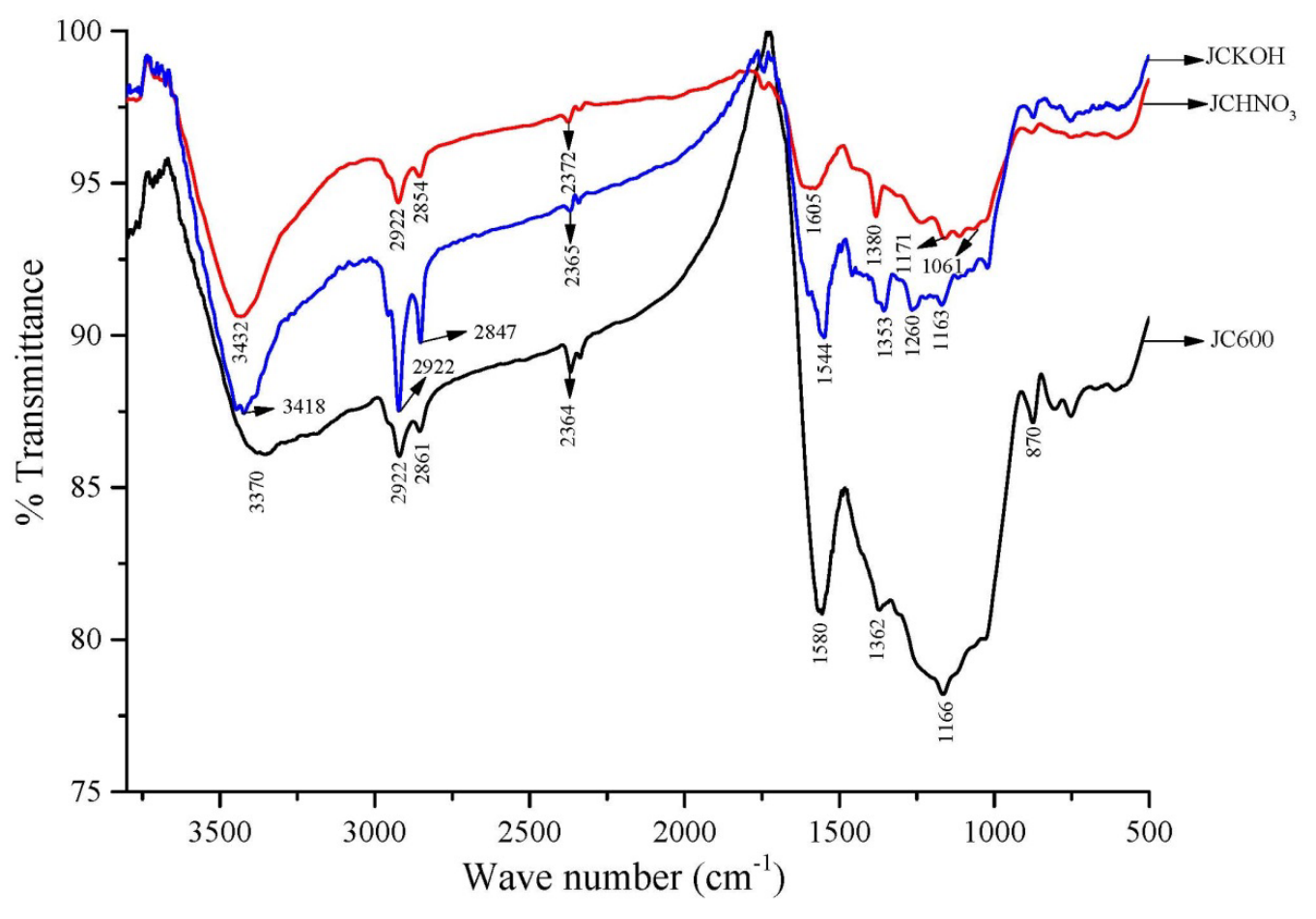

Figure 4. FTIR analysis of activated carbon samples.

\subsection{TGA analysis}

TGA plots of $\mathrm{JC}_{600}$ (at IR 1), $\mathrm{JC}_{\mathrm{HNO}_{3}}$ and $\mathrm{JC}_{\mathrm{KOH}}$ were shown in Figure.5. In all TGA plots before reaching $150^{\circ} \mathrm{C}$ temperature, there was little fall (8-10\%) in weight of each carbon. In this region moisture content of carbon samples was removed. From this temperature, there was a gradual decrease in weight of each carbon sample. However, at $890^{\circ} \mathrm{C}$, the fall is about $52 \%$ in $\mathrm{JC}_{\mathrm{HNO}_{3}}$ and $43 \%$ in $\mathrm{JC}_{\mathrm{KOH}}$. It is may due to the difference in presence of surface oxygen functional groups in these two carbons. And these oxygen functional groups might have reacted with carbon to escape as $\mathrm{CO}_{2}$ and $\mathrm{CO}$ gases. $\mathrm{In}_{6} \mathrm{JC}_{600}$, the fall is only $28 \%$ at this temperature. It may be due to the presence of less number of oxygen functional groups. This observation is also in good agreement with the FTIR analyses of corresponding activated carbons shown in Figure.4. 
(a)

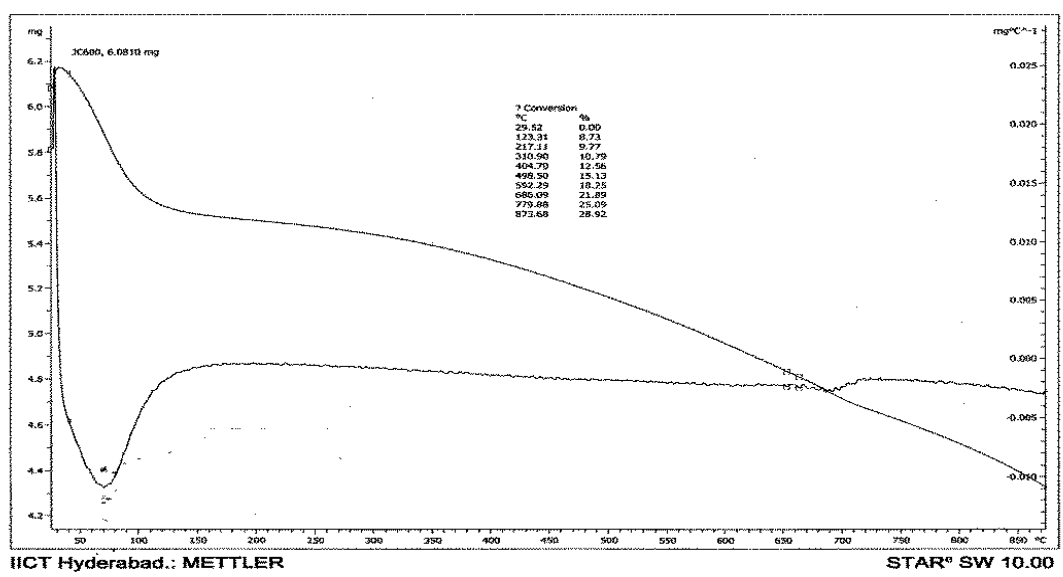

(b)

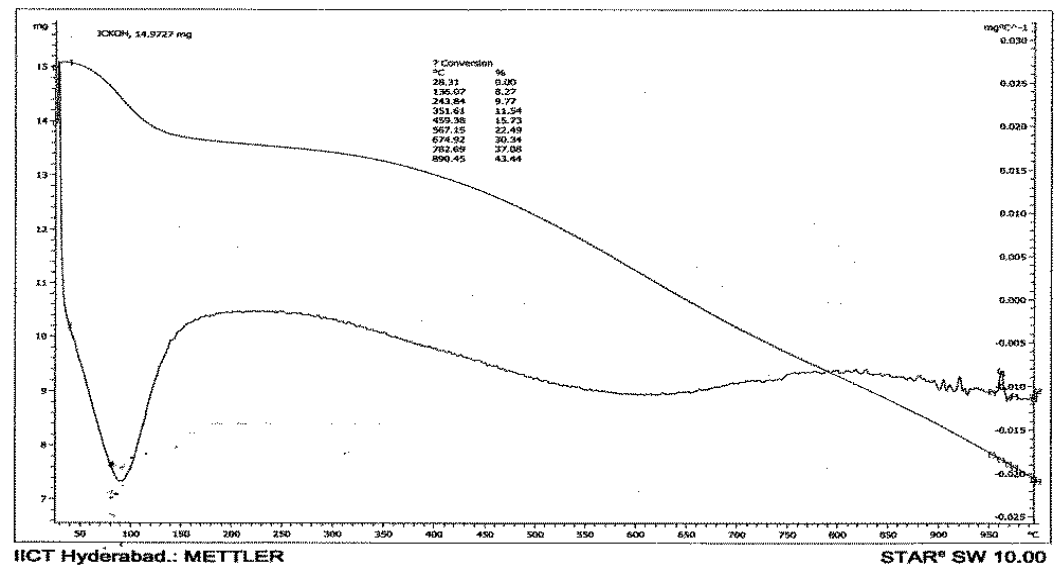

(c)

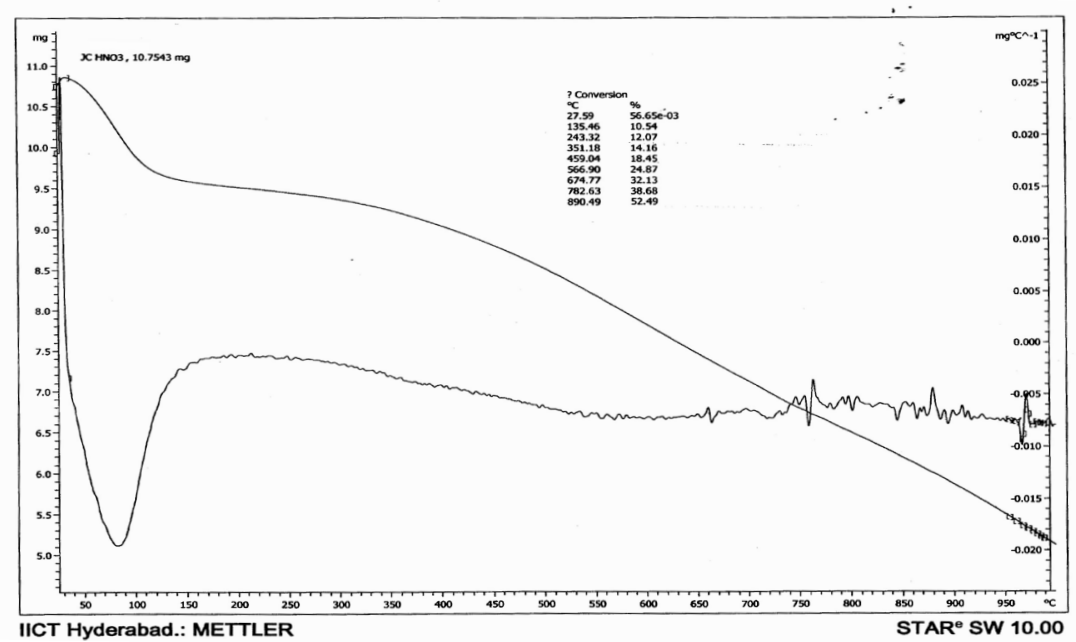

Figure 5. TGA of $\mathrm{JC}_{600}$ (at IR1), $\mathrm{JC}_{\mathrm{HNO}_{3}}$ and $\mathrm{JC}_{\mathrm{KOH}}$.

\subsection{SEM analysis}

SEM images of $\mathrm{JC}_{500}, \mathrm{JC}_{600}$ and $\mathrm{JC}_{700}$ carbons of $\mathrm{K}_{2} \mathrm{CO}_{3}$ impregnation ratio 1were shown in Figure.6. For comparison, SEM image of $\mathrm{JC}_{\text {Non-activated }}$ was also included. When compared with SEM images of impregnated activated carbons, pores are not observed in $\mathrm{JC}_{\text {Non-activated. Pore }}$ structure development was started in $\mathrm{JC}_{500}$. But in $\mathrm{JC}_{600}$ more number of pores was developed. When the temperature is reached to $700^{\circ} \mathrm{C}$ (shown in Figure.6(d)), pores were ruptured and their size was increased. It supports the observation of conversion of micropores to meso- and macro pores in DFT analysis. 
(a)

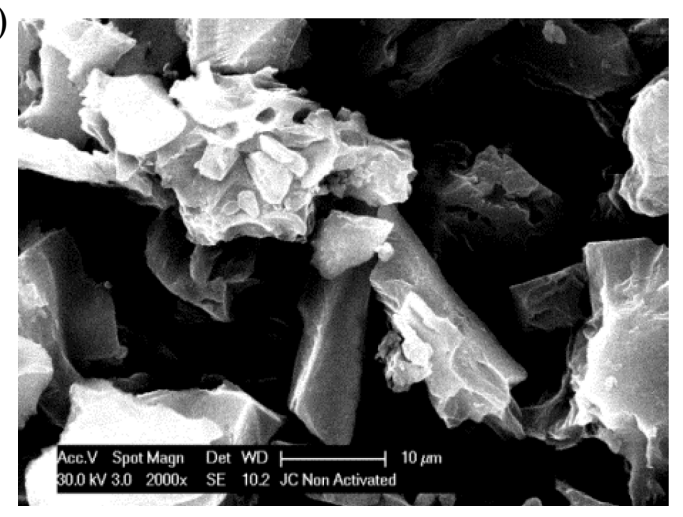

(c)

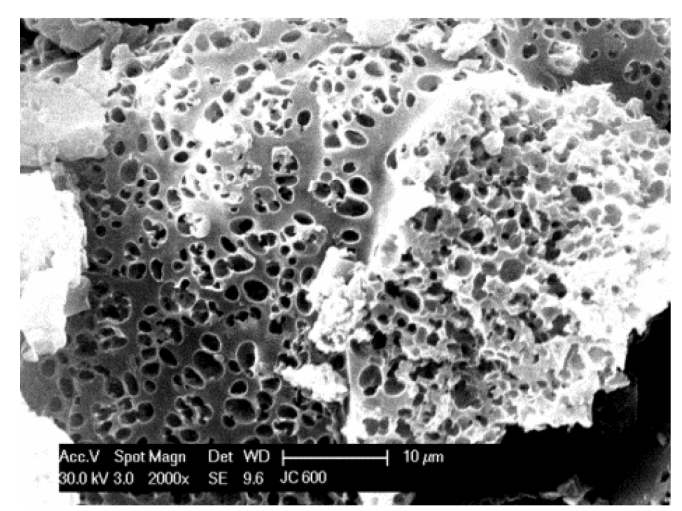

(b)

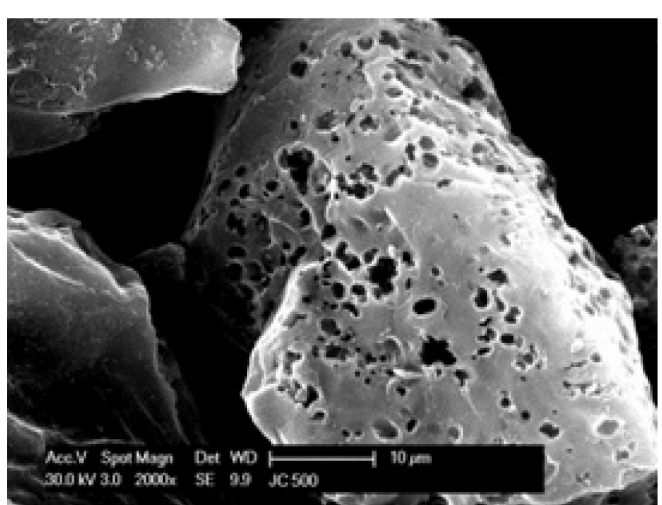

(d)

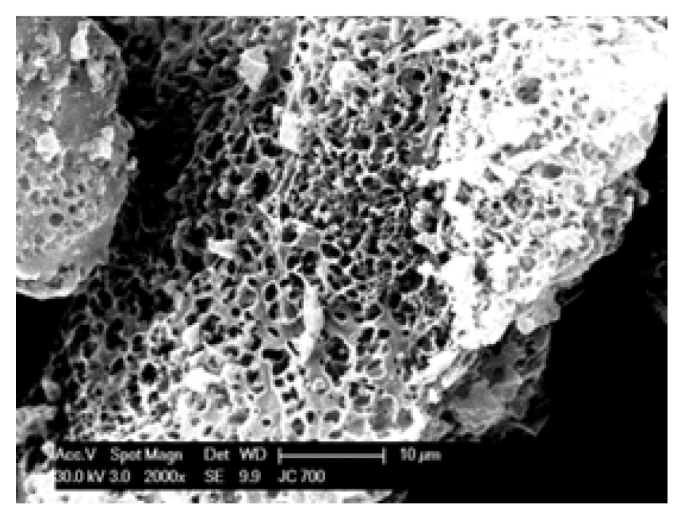

Figure 6. SEM Images of (a) $\mathrm{JC}_{\text {Non-activated }}$;(b) $\mathrm{JC}_{500}$ (at IR1) ;(c) $\mathrm{JC}_{600}$ (at IR1) and (d) $\mathrm{JC}_{700}$ (at IR1).

\subsection{X-Ray diffraction}

The XRD pattern of $\mathrm{JC}_{600}$ (at IR 1), $\mathrm{JC}_{\mathrm{HNO}_{3}}$ and $\mathrm{JC}_{\mathrm{KOH}}$ was shown in Figure.7. The layer dimension $\mathrm{L}_{\mathrm{a}}$ parallel to the basal plane of the graphite is calculated from the (100) reflection. The dimension perpendicular to the basal plane $\left(\mathrm{L}_{\mathrm{c}}\right)$ was obtained from the $(002)$ reflection.

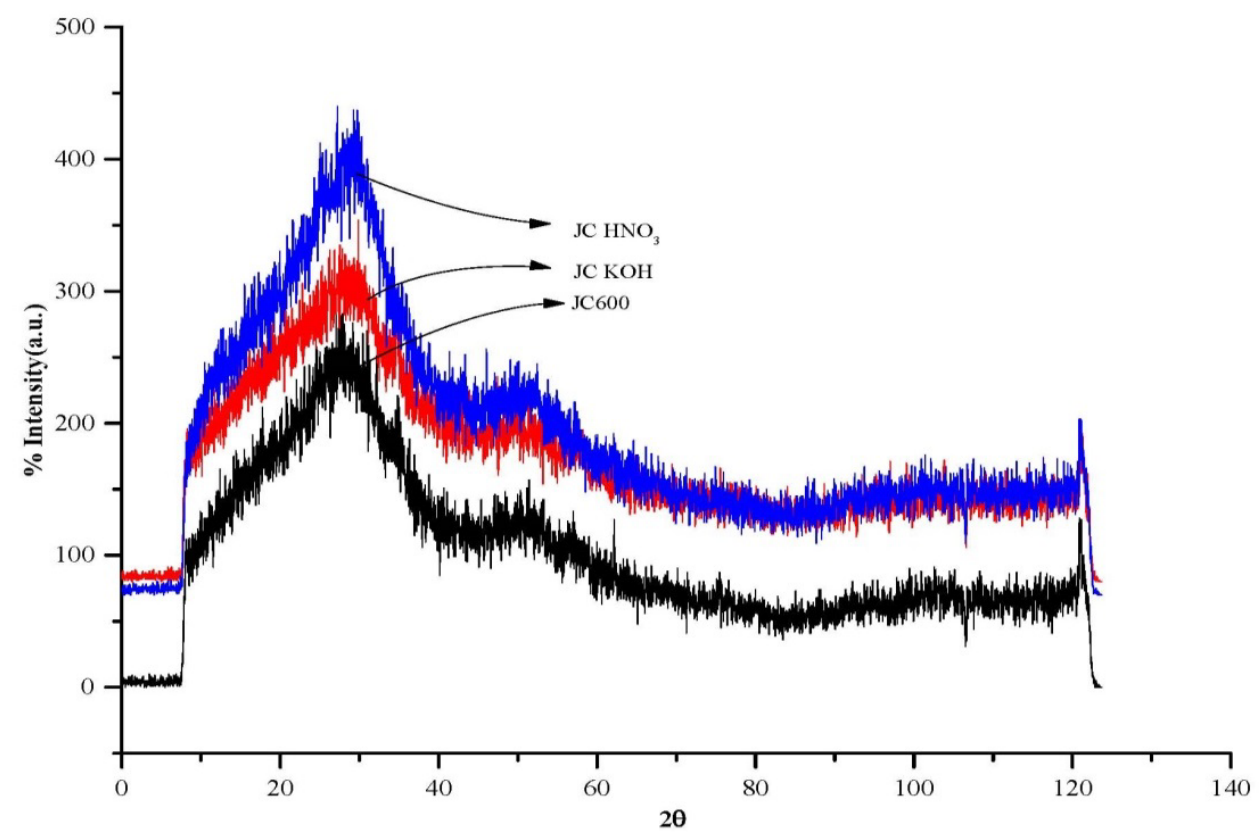

Figure 7. $\mathrm{XRD}$ graph of $\mathrm{JC}_{600}$ (at IR1), $\mathrm{JC}_{\mathrm{HNO}_{3}}$ and $\mathrm{JC}_{\mathrm{KOH}}$. 
The interlayer spacing $\mathrm{d}_{002}$ is determined by using the Bragg's equation as follows:

$$
d=\frac{\lambda}{2 \operatorname{Sin} \theta}
$$

Where $\lambda$ is the $\mathrm{X}$-ray wavelength and $\theta$ is the scattering angle for the peak position.

$$
L=\frac{K \lambda}{B \operatorname{Cos} \theta}
$$

Where $\mathrm{L}_{\text {is }} \mathrm{L}_{\mathrm{c}}$ or $\mathrm{L}_{\mathrm{a}}$, $\mathrm{B}$ is the half-width of the peak in radians, and $\mathrm{K}$ is the shape factor. The shape factor $\mathrm{K}$ depends on the lattice dimension and the values $\mathrm{K}=0.9$ and $\mathrm{K}=1.84$ were used for calculation of $\mathrm{L}_{\mathrm{c}}$ and $\mathrm{L}_{\mathrm{a}}$, respectively.

The values of $\mathrm{d}_{002}, \mathrm{~L}_{c}$, and $\mathrm{L}_{\mathrm{a}}$ of selected activated carbons were tabulated in Table 4 . The XRD curves were shown in Figure. 7. For these activated carbons, the diffraction profiles exhibited broad peaks at around 27 and $48^{\circ}$ which are assigned to the reflection from $\left(\begin{array}{lll}0 & 0 & 2\end{array}\right)$ and $\left(\begin{array}{lll}1 & 0 & 0\end{array}\right)$ planes, respectively. The occurrence of broad peaks at these $2 \theta$ indicates an increasing regularity of crystal structure and resulted in better layeral alignment [20].

Table. 4. XRD parameters of $\mathrm{JC}_{600}, \mathrm{JC}_{\mathrm{HNO}_{3}}$ and $\mathrm{JC}_{\mathrm{KOH}}$.

\begin{tabular}{|c|c|c|c|}
\hline Sample & $\begin{array}{c}d_{002} \\
(\mathrm{~nm})\end{array}$ & $\begin{array}{c}L_{\mathrm{c}} \\
(\mathrm{nm})\end{array}$ & $\begin{array}{c}L_{\mathrm{a}} \\
(\mathrm{nm})\end{array}$ \\
\hline $\mathrm{JC}_{600}$ & 0.319 & 1.85 & 2.25 \\
\hline $\mathrm{JC}_{\mathrm{HNO}_{3}}$ & 0.323 & 1.98 & 2.17 \\
\hline $\mathrm{JC}_{\mathrm{KOH}}$ & 0.313 & 1.98 & 2.39 \\
\hline
\end{tabular}

From the $\mathrm{XRD}$ graph, it is clearly evident that $\mathrm{JC}_{600}$ (at IR1) structurally does not alter during liquid phase activation with $\mathrm{HNO}_{3}$ and $\mathrm{KOH}$. The $\mathrm{L}_{\mathrm{a}}, \mathrm{L}_{\mathrm{c}}$ and $\mathrm{d}_{002}$ values of all the three carbons indicate that no appreciable change had happened to $\mathrm{JC}_{600}$ (at IR1) while introducing different functional groups upon carbon surface.

\section{CONCLUSION}

The selected JWM can be used as a precursor for preparation of activated carbon as it gave good yield. The presence of both micro and mesopores on $\mathrm{JC}_{600}$ (at IR1) may fecilitate the adsorption of different types of pollutants with varying sizes. All the three activated carbons, viz., $\mathrm{JC}_{600}$ (at IR 1), $\mathrm{JC}_{\mathrm{HNO}_{3}}$ and $\mathrm{JC}_{\mathrm{KOH}}$ were found to contain nearly similar texture but have different functional groups and zero point charges. Hence these carbons can be used to adsorb different types of organic pollutants from water.

\section{References}

[1] M.L. Godino-Salido, R. Lopez-Garzon, M.D. Gutierrez-Valero, P. Arranz-Mascaros, M. Melguizo-Guijarro, M.D.L. Torre, V. Gomez-Serrano, M. Alexandre-Franco, D. Lozano-Castello, D. Cazorla-Amoros, M. Domingo-Garcia, Materials Chemistry and Physics, 143 (2014) 1489-1499.

[2] H. Marsh, F. Rodriguez-Reinoso, Elsevier Science \& Technology Books (2006) 401-462.

[3] G. Newcombe, R. Hayes, M. Drikas, Colloids Surf. A 78 (1993) 65-71.

[4] Y. Diao, W.P. Walawender, L.T. Fan, Bioresour. Technol81 (2002) 45-52.

[5] D. Prahas, Y. Kartika, N. Indraswati, S. Ismadji, Chemical Engineering Journal 140 (2008) 3242 .

[6] D. Adinta, W.M.A.W. Daud, M.K. Aroua, Bioresource Technology 98 (2007) 145-149. 
[7] D.W. McKee, Fuel 62 (1983) 170-175.

[8] J. Hayashi, T. Horikawa, I. Takeda, K. Muroyama, F.N. Ani, Carbon 40 (2002) 2381-2386.

[9] K. Okada, N. Yamamoto, Y. Kameshima, A. Yasumori, J. Colloid Interface Sci 262 (2003) $179-193$.

[10] X. Xiang, E. Liu, L. Li, Y. Yang, H. Shen, Z. Huang, Y. Tian, J. Solid State Electrochem 15 (2011) 579-585.

[11] X.J. Jin, Z.M. Yu, Y.U. Wu, Cellulose Chem. Technol 46 (2012) 79-85.

[12] J.L. Figureueiredo, M.F.R. Pereira, M.M.A. Freitas, J.J.M. Orfao, Carbon 37 (1999) 13791389.

[13] J.A. Menendez, J. Phillips, B. Xia, L.R. Radovic, Langmuir 12 (1996) 4404-4410.

[14] M.H. Isa, L.S. Lang, F.A.H. Asaari, H.A. Aziz, N.A. Ramli, J.P.A. Dhas, Dyes and Pigments 74 (2007) 446-453.

[15] J.J. Venter, M.A. Vannice, Carbon 26 (1988) 889-902.

[16] B.J. Meldrum, C.H. Rochester, J. Chem. Soc., Faraday Trans 86 (1990) 1881-1884.

[17] M. Starsinic, R.L. Taylor, Jr. P.L. Walker, P.C. Painter, Carbon 21 (1983) 69-74.

[18] P.E. Fanning, M.A. Vannice, Carbon 31 (1993) 721-730.

[19] E. Papirer, J. Dentzer, S. Li, J.B. Donnet, Carbon 29 (1991) 69-72.

[20] T. Yang, A.C. Lua, Mater. Chem. Phys 100 (2006) 438-444. 